\title{
Study of Fastness, UV Protection, Deodorization and Antimicrobial Properties of Silk Fabrics Dyed with the Liquids Extracted from the Gallnuts, Areca Nuts, and Pomegranate Peels
}

\author{
Jin Soun. Jung ${ }^{a}$ \\ Department of Fashion Design, Semyung University, South Korea
}

\begin{abstract}
The purpose of this research is to study the fastness, UV-protection, deodorization, and antimicrobial properties of silk fabrics dyed with liquids extracted from the gallnuts, areca nuts, and pomegranate peels.
\end{abstract}

\section{Introduction}

In textile industry, to synthetic dyestuffs and pigments are widely used because of their various range of colours, better colour fastness properties and low prices [1]. However, synthetic dyestuffs and pigments are ruled out by many producers because of their toxicity and carcinogenic effect, being not bio-degradable as well ecological [2]. Recently, the textile finishing industry tends to restrict the use of such synthetic dyestuffs and pigments in order for human health and environmental purposes. As a result, the use of natural dye has begun to increase for their better properties as being biodegradable, non-toxic, origination no problem to human health and waste water contaminant [3-5]. Natural dyes are environmental friendly, low toxic and less allergenic. Due to these advantages, over the last decade the use of natural dyes has gained momentum in food, pharmaceutical, cosmetic and textile dyeing industry [6]. For many years, scientists have investigated the deodorizing/aroma [7], insect-repellent [8], flame retardant [9], protection against to UV rays [10] of plants dyeing and usability in the textile industry. Unlike the synthetic dyes, colorants derived from the nature are thought to be safe because of their non-toxic, non-carcinogenic and biodegradable nature [11]. Natural dyes mainly consist of phenolic compounds which play an important role in plant growth and reproducibility. Many of them have antioxidant activity and are also considered as antibacterial and anti-inflammatory compounds. They have been widely used as herbal medicines as well as natural dyeing agents. Phenolic compounds based on their different chemical structure, are divided to groups corresponding to flavonoids, quinones, curcuminoids and tannins [12]. Tannin is an astrigent vegetable product found in awide variety of plant such as bark, wood, fruit pods, leaves, roots and plant galls. Tannins are defined as naturally occurring water soluble polyphenolic compounds of high molecular

\footnotetext{
${ }^{\mathrm{a}}$ Corresponding author: bobejin@semyung.ac.kr
}

weight (about 500-3000) containing phenolic hydroxyl groups to enable them to form effective crosslinks between proteins and other macromolecules [13].

The purpose of this research is to study the fastness, UV-protection, deodorization, and antimicrobial properties of silk fabrics dyed with the liquids extracted from the gallnuts, areca nuts, and pomegranate peels contained tannins. The light, dry cleaning, rub, and perspiration fastness of the dyed silk fabrics was evaluated. The UV protection factor of the dyed silks with SPF calculated in wavelength range of 290-400 nm range. The deodorization activity was made from concentration of residual ammonia gas in a container. The antimicrobial activity of the dyed silks was measured against Staphylococcus aureus and Klebsiella pneumoniae.

\section{Theoretical background}

\subsection{Gallnut}

Gallnuts are outgrowths of plant tissues produced when irritants are released by the larvae of gall insects such as those of the Cynipidae family, the gall wasps. This extract contains the highest naturally occurring levels of tannin (gallotannin, 50-75\%), as well as smaller molecules such as gallic acid and ellagic acid. Additionally, this extract is known to possess pharmaceutical properties, including anti-inflammatory, antibacterial, and detoxifying properties [14]. Figure 1 showed the chemical structure of tannin(Gallnut tannin) contained in gallnut and image of gallnut dried.
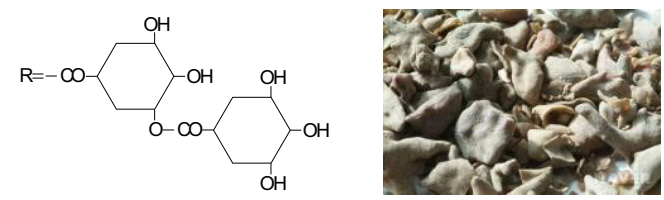
Figure 1. Chemical structure of tannin(Gallnut tannin) contained in gallnuts and image of gallnuts dried.

\subsection{Areca nut}

Areca nut (Areca catechu L.), belonging to the family Palmae(or Arecaceae), native to Malaysia, widely cultivated in Indonesia, Sri Lanka, Hainan province, Guangdong province, Yunnan province and other places in Southeast Asia, is one of th most widely used SouthChina medicine resources [15]. Areca nut is popular chewable items used in traditional herbal medicine [16-18]. Areca nut exhibits multiple therapeutic properties like, aphrodisiac [19], antihypertensive [20, 21], wound healing [22], hypoglycemic [23, 24] and antidepressant [25]. It is one of the most commonly used drugs in the world, containing alkaloids, tannins, polyphenols, sugars, and lipids that have anthelmintic, antifungal, antibacterial, anti-inflammatory, and antioxidant activities [26]. Tannins are another characteristic component of Areca nut, and the main types are condensed tannins (also called proanthocyanidins). The main classes of tannins in A. catechu are the catechuins (Figure 2) [27-30].

CATECHUINS

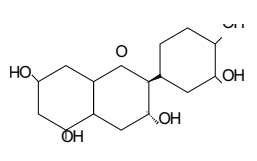

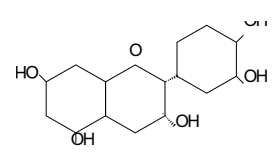

EPICATECHUINS

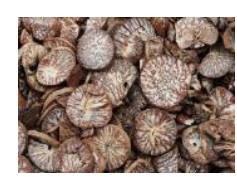

Figure 2. Chemical sructure of tannin(Catechuins and Epicatechuins) contained in areca nuts and image of areca nuts dried.

\subsection{Pomegranate}

Pomegranate (Punica granatum L.) belongs to the Punicacea family [31-33]. The cultivation of pomegranate is native to the Middle East and was later known in the Mediterranean. Pomegranate peels are rich in tannins [34-36]. They have been used traditionally for their medicinal properties as anticancer, anti-inflammatory, antioxidant and antithelminthic [37, 38] and for other purposes such as tanning, dyeing [39, 40] and heavy metal removal [41]. Pomegranate peels are characterized by an interior network of membranes comprising almost $26-30 \%$ of total fruit weight and are characterized by substantial amounts of phenolic compounds, including flavonoids (anthocyanins, catechins and other complex flavonoids) and hydrolysable tannins (punicalin, pedunculagin, punicalagin, gallic and ellagic acid) [42-44]. Gallic acid, ellagic acid and punicalagin, in addition to their free radical-scavenging properties, also possess antibacterial activites against intestinal flora, particularly enteric pathogens, i.e., Escherichia coli, Salmonella spp. Shigella spp., as well as Vibrio cholera [45-48]. Figure 3 showed the chemical structure of pomegranate tannin(Ellagic tannin) contained in pomegranate peels and image of pomegranate peels dried.

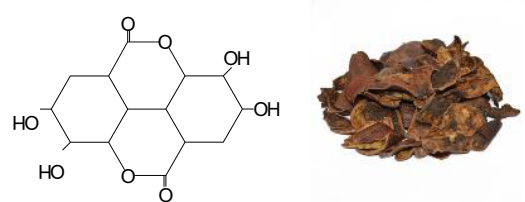

Figure 3. Chemical structure of pomegranate tannin(Ellagic tannin) contained in pomegranate peels and image of pomegranate peels dried.

\section{Experimental materials and methods}

\subsection{Experimental materials}

Silk: Silk used in this study was purchased from Testfabrics Inc. (West Pittston, PA)., and the characteristics are as shown on the Table 1. The silk was purchased from Testfabrics Inc. (West Pittston, PA).

Table 1. The Characteristics of silk

\begin{tabular}{lllllll}
\hline \hline \multirow{2}{*}{ Fiber } & \multirow{3}{*}{ Weave } & \multicolumn{2}{l}{ Yarn Number } & \multicolumn{2}{l}{ Fabric Counts } & Weight \\
& & Warp & Weft & Warp & Weft & $\left(\mathrm{g} / \mathrm{m}^{2}\right)$ \\
\hline Silk & Plain & 21D & 21D/2 & 56 & 39 & 26 \\
\hline \hline
\end{tabular}

Gallnut, Areca Nut, Pomegranate: Gallnuts and areca nuts were acquired from online from Cheongmyeong herbs(http://www.good1075.com), and pomegranates were purchased from a local market in Korea.

\subsection{Experimental methods}

$U V$-Vis/NIR Spectra: 1g dried gallnuts, areca nuts and pomegranate peels was added to $100 \mathrm{~m} \ell$ ethanol respectively, and they were extracted at room temperature for 24 hours, and filtered. The filtered extracts respectively were used as samples for UV-Vis analysis. The measurement of the UV-absorption characteristics was conducted in the range of 190-800 $\mathrm{nm}$ by using an ultraviolet-Visible/Near Infrared spectrophotometer (Varian Cary 5000).

FT-IR Spectra: The dried and grinded powers of gallnuts, areca nuts and pomegranate peels were analyzed with Fourier Transform Infrared Spectrometer (Bruker TENSOR27). Each samples were scanned registering the spectrum with 32 scans with a resolution of $4 \mathrm{~cm}^{-1}$ in the wave number range between 4000 and $600 \mathrm{~cm}^{-1}$.

The extraction treatment of gallnut, areca nut and pomegranate peel: Gallnuts, areca nuts and pomegranate peels were extracted in liquor ratio of 1:20 at the boiling temperature for 20minutes. Each solutions were filtered with filter paper. The process was repeated 2 times. The liquid extraction combined first and second extract liquid was used as solution for dyeing.

Mordanting: Silk fabrics were mordanted by post-mordanting method using ferric mordant $(0.2 \%)$, and liquor ratio for mordanting was kept at 1:30. Before the application of mordants, silk fabrics were soaked in distilled water. Water soaked silk fabrics were immersed 
in mordants solutions, and mordanted at $40{ }^{\circ} \mathrm{C}$ for 30 minutes with constant stirring. Mordanted silk fabrics were rinsed with distilled water to remove superfluous mordants.

Dyeing: Before the application of dyeing, silk fabrics were soaked in distilled water. Firstly silk fabrics were dyed in liquor ratio of 1:30 at the boiling temperature for 20 minutes with constant stirring. Secondly, the samples were left in the fluid for one night. Thirdly, the samples were washed with $1500 \mathrm{~m} \ell$ of cold distilled water (Three repetitions) then squeezed and dried at room temperature.

Color Fastness Tests: The light fastness of silk fabrics dyed was conducted on Fade-O-Meter(25-FR, Atlas Electric Devices Co. U.S.A) having water cooled Xenon Arc, as per test method KS K ISO B02:2005. The dry cleaning fastness of silk fabrics dyed was measured in Launder-O-Meter(Model LP2, Co. Atlas) as per the KS K ISO 105D01:2010, specification. The dry and wet rub fastness of silk fabric dyed s was tested using RubbingCrock Meter(CM-5, Atlas Electric Devices Co. U.S.A) as per the KS K ISO 0650:2011. The perspiration fastness of silk fabrics dyed was measured AATCC Perspiration Tester (PR-1, Atlas Electric Devices Co. U.S.A) as per test method KS K ISO 105E04:2010.

UV protection factor: UV-protection factor was tested using UV-Vis spectrophotometer(Varian Cary 5000) as per the KS K 0850:2014, o/d. Transmission measurements were made in $290-400 \mathrm{~nm}$ range with a 1 $\mathrm{nm}$ step. SPF was calculated according to:

\begin{tabular}{|c|c|c|c|}
\hline \multirow[t]{4}{*}{ SPF } & $=$ & $\begin{array}{l}400 \\
\Sigma \\
290\end{array}$ & $\mathrm{E}_{\lambda} \mathrm{S}_{\lambda} \Delta_{\lambda}$ \\
\hline & & 400 & \\
\hline & & $\Sigma$ & $\mathrm{E}_{\lambda} \mathrm{S}_{\lambda} \mathrm{T}_{\lambda} \Delta_{\lambda}$ \\
\hline & & 290 & \\
\hline
\end{tabular}

where $S_{\lambda}$ is the solar spectral irradiance at noon for a typical summer's day in central Italy, $E_{\lambda}$ is the CIE erythermal spectral effectiveness, $T_{\lambda}$ is the spectral transmittance of each fabric sample and $T_{\lambda}$ is the wavelength step.

Deodorization activity: Deodorizationrate was calculated according to:

$$
\text { Deodorizationrate }(\%)=\frac{\mathrm{Cb}-\mathrm{Cs}}{\mathrm{Cb}} \times 100
$$

where $C_{b}$ is residual gas concentration of control after 2hours, Cs is residual gas concentration of specimen after 2hours.

Antimicrobial Activity: The antimicrobial ability of the dyed samples to impede microbial growth and retention was tested using Staphylococcus aureus and Klebsiella pneumoniae cultures, according to an established protocol to test the antibacterial of textiles (KS K 0693). Antimicrobial activity was calculated according to: where $\mathrm{B}$ is the number of bacteria recovered from the inoculated control specimen incubated for 18hours, A is the number of bacteria recovered from the inoculated treated test specimen incubated for 18 hours.

\section{Results}

\subsection{Spectroscopic analysis by UV-Vis/NIR spectra}

Figure 4 shows the UV-Vis/NIR spectra of the ethanolic extraction solution of gallnuts, areca nuts and pomegranate peels in the range of 190-800 nm. As shown by Figure 4 and Table 2, two absorption bands are easily seen in the ranges from 190 to $250 \mathrm{~nm}$, and from 250 to $300 \mathrm{~nm}$, and another broad absorption band appears around 300-400 nm. Gallnuts presented two characteristic absorption maximum, $\lambda \max _{1}$ around $217 \mathrm{~nm}$ and $\lambda \max _{2}$ at $279 \mathrm{~nm}$. Spectra of areca nuts classified as condensed tannin, presented two characteristic absorption maximum, $\lambda \max 1$ around $224 \mathrm{~nm}$ and $\lambda \max 2$ at $280 \mathrm{~nm}$. Pomegranate peels absorbed with two $\lambda \max$ at 250 and $368 \mathrm{~nm}$

\subsection{Spectroscopic analysis by FT-IR spectra}

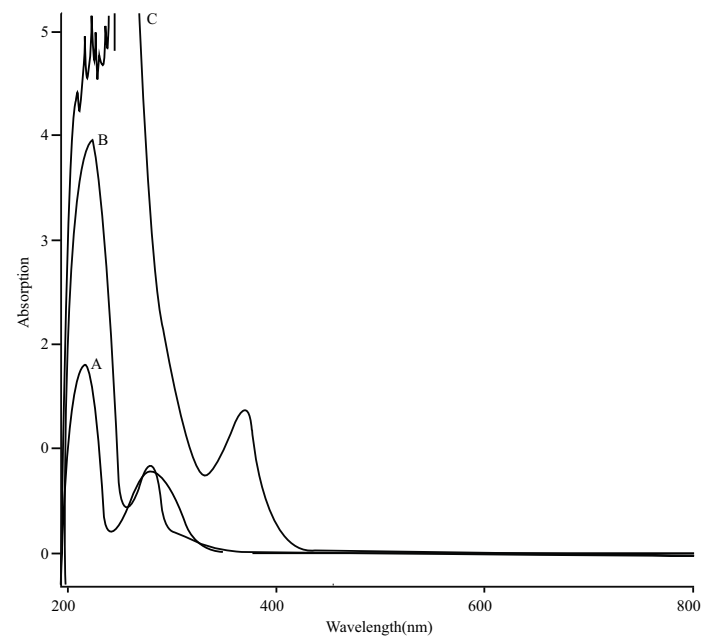

Figure 4. UV-VIS Spectra of ethanol extraction solution of gallnuts(A), areca nuts(B) and pomegranate peels(C)

Table 2. Wavelength and absorption of gallnuts, areca nuts and pomegranate peels

\begin{tabular}{lcc}
\hline \hline \multicolumn{1}{c}{ Samples } & Wavelength(nm) & Absorption \\
\hline \multirow{2}{*}{ Gallnut } & 217 & 1.813 \\
& 279 & 0.771 \\
\hline \multirow{2}{*}{ Areca nut } & 224 & 4.001 \\
& 280 & 0.856 \\
\hline \multirow{2}{*}{ Pomegranate peel } & 258 & 6.654 \\
& 368 & 1.366 \\
\hline \hline
\end{tabular}

\subsection{Fastness properties}

Fastness properties of silk fabrics dyed were given in Table 3. The samples showed mostly good light and dry 
cleaning fastness with 4 grade. Wet rub fastness was found to be relatively better than dry rub fastness. Perspiration fastness was all excellent grades $4 \sim 5$ except for the 3 4 grades from discoloration by acidity and alkalinity.

Table 3. The fastness properties of silk fabrics dyed

\begin{tabular}{|c|c|c|c|}
\hline \multicolumn{3}{|l|}{ Dyeing Fastness } & Grade \\
\hline \multicolumn{3}{|l|}{ Light Fastness } & 4 \\
\hline Dry Cleaning & \multicolumn{2}{|c|}{ Discoloration } & 4 \\
\hline Fastness & \multicolumn{2}{|c|}{ Solvent Contamination } & 4 \\
\hline \multirow{2}{*}{ Rub Fastness } & \multicolumn{2}{|l|}{ Dry } & 2 \\
\hline & \multicolumn{2}{|l|}{ Wet } & $2 \sim 3$ \\
\hline \multirow{7}{*}{$\begin{array}{l}\text { Perspiration } \\
\text { Fastness }\end{array}$} & \multirow{4}{*}{ Acidity } & Discoloration & $3 \sim 4$ \\
\hline & & Contamination(Silk) & 4 \\
\hline & & Contamination(Cotton & \multirow{2}{*}{$4 \sim 5$} \\
\hline & & ) & \\
\hline & \multirow{3}{*}{ Alkalinity } & Discoloration & $3 \sim 4$ \\
\hline & & Contamination(Silk) & 4 \\
\hline & & $\begin{array}{l}\text { Contamination(Cotton } \\
\text { ) }\end{array}$ & $4 \sim 5$ \\
\hline
\end{tabular}

\subsection{UV Protection Rate}

UV protection rate of dyed silk fabrics was shown in Table 4. UV-A protection rate of the samples in wavelength range of 290-400 $\mathrm{nm}$ showed $98.3 \%$, and UV-B protection rate of the samples in wavelength range of $290 \sim 315 \mathrm{~nm}$ showed $98.4 \%$. As described above, the samples appeared very good UV protection rate.

Table 4. UV protection rate of silk fabrics dyed

\begin{tabular}{lll}
\hline \hline & \multicolumn{2}{l}{ UV Protection Rate (\%) } \\
\cline { 2 - 3 } & UV-A & UV-B \\
\hline Untreated Silk & - & - \\
Silk Fabric & 98.3 & 98.4 \\
Dyed & & \\
\hline \hline
\end{tabular}

\subsection{Deodorization activity of silk fabric dyed}

Table 5 showed deodorization activity of dyed silk fabrics. As outlined in Table 5, the samples appeared excellent deodorization activity over $99 \%$ even after $120 \mathrm{~min}$. test.

Table 5. Deodorization activity of silk fabric dyed

\begin{tabular}{|c|c|c|}
\hline & & $\begin{array}{l}\text { Deodorization Activity } \\
(\%)\end{array}$ \\
\hline \multirow[t]{2}{*}{ Untreated Silk } & & - \\
\hline & 30min. & over $99 \%$ \\
\hline Silk Fabric & 60min. & over $99 \%$ \\
\hline \multirow[t]{2}{*}{ Dyed } & $90 \mathrm{~min}$. & over $99 \%$ \\
\hline & $120 \mathrm{~min}$. & over $99 \%$ \\
\hline
\end{tabular}

\subsection{Antimicrobial ativity of silk fabric dyed}

The antimicrobial activity of dyed silk fabrics against Staphylococcus aureus and Klebsiella pneumoniae was assessed. Table 6 showed the antiimicrobial activity of dyed silk fabrics. The samples appeared high antiimicrobial activity activity of $99.9 \%$ against Staphylococcus aureus and Klebsiella pneumoniae.

Table 6. Antimicrobial activity of silk fabrics dyed

\begin{tabular}{lcc}
\hline \hline & \multicolumn{2}{l}{ Reduction of Bacteria (\%) } \\
\cline { 2 - 3 } & $\begin{array}{l}\text { Staphylococcus } \\
\text { aureus }\end{array}$ & $\begin{array}{l}\text { Klebsiella } \\
\text { pneumoniae }\end{array}$ \\
\hline $\begin{array}{l}\text { Untreated Silk } \\
\text { Silk Fabric }\end{array}$ & - & - \\
Dyed & 99.9 & 99.9 \\
\hline \hline
\end{tabular}

\section{Conclusion}

Among dyeing fastness of dyed silk fabrics, light and dry cleaning fastness showed 4 grade. Rub fastness was 2 3 grade. Perspiration fastness was $3 \sim 5$ grade. The dyed silk fabrics in wavelength range of 290-400 nm appeared UV protection rate of $98.3 \%$, and UV-B protection rate in wavelength range of $290 \sim 315 \mathrm{~nm}$ showed $98.4 \%$. Deodorization activity of the dyed silk fabrics appeared over 99\%. The dyed silk fabrics showed high antibacterial activity of $99.9 \%$ against Staphylococcus aureus and Klebsiella pneumoniae.

\section{Acknowledgment}

This work was supported by the Ministry of Education of the Republic of Korea and the National Research Foundation of Korea (NRF-2015S1A5A2A01009314).

\section{References}

1. L. G. Angelini, A. Bertoli, S. Rolandelli, L. Pistelli, Agronomic potential of Reseda Luteola L. as new crop for natural dyes in textiles production, Industrial Crops and Products, 17, 199-207 (2003)

2. N. A. Ibrahim, A. R. El-Gamal, M. Gouda, F. Mahrous, A new approach for natural dyeing and functional finishing of cotton cellulose, Carbohydrate Polymers, 82, 1205-1211 (2010)

3. T. Bechtold, M. A. Amalid, R. Mussak, Natural dyes for textile dyeing: A comparison of methods to assess the quality of Canadian golden rod plant material, Dyes and Pigments, 75, 287-293 (2007)

4. A. Barka, A. Assabbanea, A. Nounah, L. Laanab, Y. L. Ichou, Removal of textile dyes from aqueous solutions by natural phosphate as a new adsorbent, Desalination, 235, 264- 275 (2009)

5. S. Baliarsingh, A. K. Panda, J. Jena, T. Das, Exploring sustainable technique on natural dye extraction from native plants for textile: Identification of colourants, colourimetric analysis of dyed yarns and their antimicrobial evaluation, Journal of Cleaner Production, 37, 257-264 (2012) 
6. A. K. Samanta, P. Agarwal, Application of natural dyes on textiles, Indian Journal of Fibre Textile Research, 34, 384-399 (2009)

7. W. Sricharussin, C. Sopajaree, T. Maneerung, N. Sangsuriya, Modification of cotton fabrics with $b$ cyclodextrin derivative for aroma finishing, Journal of Textile Insitute, 100, 682-687 (2009)

8. M. M. M. Specos, J. J. Garcia, J. Tornesello, P. Marinoa, M. D. Vecchia, M. V. D. Tesoriero, L. G. Hermida, Microencapsulated citronella oil for mosquito repellent finishing of cotton textiles, Transactions of the Royal Society of Tropical Medicine Hygiene, 104, 653-658 (2010)

9. L. Huang, M. Gerber, J. Lu, A. E. Tonelli, Formation of a flame retardantcyclo dextrin inclusion compound and its application as a flame retardant for poly (ethylene terephthalate), Polymer Degration and Stability, 71, 279- 284 (2001)

10. D. Grifoni, L. Bacci, G. Zipoli, L. Albanese, F. Sabatini, The role of natural dyes in the UV protection of fabrics made of vegetable fibres, Dyes Pigments, 91, 279-285 (2011)

11. M. Yusuf, A. Ahmad, M. Shahid, M. I. Khan, S. A. Khan, N. Manzoor, F. Mohammad, Assessment of colorimetric, antibacterial and antifungal properties of woollen yarn dyed with the extract of the leaves of henna (Lawsonia inermis), Journal of Cleaner Production, 27, 42-50 (2012)

12. F. Alihosseini, G. Sun, Recent progresses in antibacterial dyes, H and PC Tod., 4, 17-21 (2008)

13. K. Ramakrishnan, S. R. Selve, R. Shubha, Tannin and its analytical techniques, Indian Chemical Engineering Section A, 48, 2, 88- 93 (2006)

14. Park AY, Kim IY, Song WS., The effect of gallnut mordanting on gromwell dyed silk fabric, Journal of the Korean Society of Clothing and Textiles, 33, 256 - 265 (2009)

15. J. L. Huang, High-performance liquid chromatographic determi- nation of the alkaloids in betel nut, Journal of Chromatography, 475, 447-450 (1989)

16. M. S. Amudhan, V. H. Begum, K. B. Hebbar, A review on phytochemical and pharmacological potential of Areca catechu L. seed, International Journal Pharmaceutical Science and Research, 3, 4151-4157 (2012)

17. Anonymous, Dictionary of Chinese Materia Medica, Science and Technology Press of Shanghai, China: Shanghai, 2525-2528, (1977)

18. C. D. Heatubun, J. Dransfield, T. Flynn, S. S. Tjitrosoedirdjo, J. P. Mogea, W. Baker, A monograph of the betel nu tpalms(Areca: Arecaceae) of East Malesia, Botanical Journal of the Linnean Society, 168, 147-173 (2012)

19. S. A. Norton, Betel: Consumption and consequences, Journal of the American Academy of Dermatology, 37, $81-88$ (1998)

20. J. Inokuchi, H. Okabe, T. Yamauchi, A. Nagamatsu, G. Nonaka, I. Nishioka, Antihypertensive substance in seeds of Areca catechu L., Life Sciences, 38, 1375 - 1382 (1986)
21. Y. W. Xie, H. X. Xuc, H. Dongc, R. R. Fiscus, P. H. Paul, Role of nitric oxide in the vasorelaxant and hypotensive effects of extracts and purified tannins from Geum japonicum, Journal of Ethnopharmacology, 109, 128- 133 (2007)

22. S. Azeez, S. Amudhan, S. Adiga, N. Rao, N. Rao, L.A. Udupa, Wound healing profile of Areca catechu extracts on different wound models in wistar rats, Kuwait Medical Journal, 39, 1) 48- 52 (2007)

23. J. K. Grover, S. Yadav, V. Vats, Medicinal plants of India with anti-diabetic potential, Journal of Ethnopharmacology, 81, 81- 100 (2002)

24. P. K. Mukherjee, K. Maiti, K. Mukherjee, P. J. Houghton, Leads from Indian medicinal plants with hypoglycemic potentials, Journal of Ethnopharmacology, 106, 1-28 (2006)

25. A. Dar, S. Khatoon, Behavioral and biochemical studies of dichloromethane fraction from the Areca catechu nut, Pharmacology Biochemistry and Behavior, 65, 1, 1-6 (2000)

26. G. W. Staples, R. F. Bevacqua, Areca catechu (betel nut palm), Available at http://www.webalice.it/siamseeds/Database/Arecacatechu-betel-nut (2006)

27. Y. T. Ma, F. L. Hsu, S. J. Lan, C. F. Chen, Tannins from betel nuts, Journal of Chinese Chemical Society, 4, 77-81 (1996)

28. G. I. Nonaka, F. L. Hsu, I. Nishioka, Structures of dimeric, trimeric, and tetrameric procyanidins from Areca catechu L., Journal of Chemical Society Chemistry Communication, 9, 781- 783 (1981)

29. Anonymous, Chinese Material Medica, Science and Technology Press of Shanghai, China: Shanghai, 8, 439- 648 (1999)

30. W. Q. Yang, H. C. Wang, W. J. Wang, Y. Wang, X. Q. Zhang, W. C. Ye, Chemical constituents fromthefruitsof Areca catechu, Journal of Chinese Medical Materials, 35, 400- 402 (2012)

31. V. Akbarpour, K. Hemmati, M. Sharifani, Physical and chemical properties of pomegranate (Punica granatum L.) fruit in maturation stage, AmericanEurasian Journal of Agricultural \& Environmental Sciences, 6, 411-416 (2009)

32. M. Ozgen, C. Durgac, S. Serc, C. Kaya, Chemical and antioxidant properties of pomegranate cultivars grown in the Mediterranean region of Turkey, Food Chemistry, 111, 7703-7706 (2008)

33. R. A. Newman, E. P. Lansky, M. L. Block, Pomegranate: The Most Medicinal Fruit, 1st ed. W. Roberta, Ed. USA: Waddell (2007)

34. N. S. Al-Zoreky, Antimicrobial activity of pomegranate (Punica granatum L.) fruit peels, International Journal of Food Microbiology, 134, 244- 248 (2009)

35. T. B. Machado, A. V. Pinto, M. C. F. R. Pinto, I. C. R. Leal, M. G. Silva, A. C. F. Amaral, R. M. Kuster, K. R. Nett-dosSantos, In vitro activity of Brazilian medicinal plants, naturally occurring naphthoquinones and their analogues against methicillin-resistant Staphylococcus aureus, 
International Journal of Antimicrobial Agents, 21, 279- 284 (2003)

36. S. Voravuthikunchai, A. Lortheeranuwat, W. Jeeju, T. Sririrak, S. Phongpaichit, T. Supawita, Effective medicinal plants against enterohaemorrhagic Escherichia coli O157:H7, Journal of Ethnopharmacology, 94, 49- 54 (2004)

37. E. A. Hayouni, K. Miled, S. Boubaker, Z. Bellasfar, M. Abedrabbad, H. Iwaskie, H. Okue, T. Matsuie, F. Limama, M. Hamdi, Hydroalcoholic extract basedointment from Punica granatum L. peels with enhanced in vivo healing potential on dermal wounds, Phytomedicine, 18, 976- 984 (2011)

38. G. Mousavinejad, Z. Emam-Djomeh, K. Rezaei, M. H. H. Khodaparast, Identification and quantification of phenolic compounds and their effects on antioxidant activity in pomegranate juices of eight Iranian cultivars, Food Chemistry, 115, 1274- 1278 (2009)

39. A. Adeel, I. A. Ali Shaukat Bhatti, F. Zsila, Dyeing of cotton fabric using pomegranate (Punica granatum) aqueous extract, Asian Journal of Chemistry, 21, 3493- 3499 (2009)

40. J. U. Lloyd, Punica granatum, second ed. Chicago (consulted

in: http://swsbm.henriettesherbal.com/ManualsOther/Pu nica granatum Lloyd (April 2001)

41. T. S. Najim, S. A. Yassin, Removal of Cr (VI) from aqueous solution using modified pomegranate peel: equilibrium and kinetic studies, European Journal of Chemistry, 6, S129-S142 (2009)

42. F. Afaq, M. Saleem, C. G. Krueger, J. D. Reed, H. Mukhtar, Anthocyanin- and hydrolyzable tannin-rich pomegranate fruit extract modulates MAPK and NFkappaB pathways and inhibits skin tumorigenesis in CD-1 mice, International Journal of Cancer, 113, 423-433 (2005)

43. P. S. Negi, G. K. Jayaprakasha, B. S. Jena, Antioxidant and antimutagenic activities of pomegranate peel extracts, Food Chemistry, 80, 393398 (2003)

44. M. Zahin, F. Aqil, I. Ahmad, Broad spectrum antimutagenic activity of antioxidant active fraction of Punica granatum L. peele xtracts, Mutation Research, 703, 99-107 (2010)

45. M. Aviram, N. Volkova, R. Coleman, M. Dreher, M. K. Reddy, D. Ferreira, M. Rosenblat, Pomegranate phenolics from the peels, arils, and flowers are 9antiatherogenic:studies in vivo in atheroscleroticapo lipoproteine-deficient (E0) mice and in vitro in cultured macro phages and lipoproteins, Journal of Agricultural and Food Chemistry, 56, 1148-1157 (2008)

46. J. Lu, Y. Wei, Q. Yuan, Preparative separation of punicalagin from pomegranate husk by high-speed countercurrent chromatography, Journal of Chromatography B, Analytical Technologies in the Biomedical and Life Sciences, 857, 175-179 (2007)

47. V. Pai, T. R. Chanu, R. Chakraborty, B. Raju, R. Lobo, M. Ballal, Evaluation of the antimicrobial activity of Punica granatum peel against the enteric pathogens: an in vitro study, Asian Journal of Plant Science and Research, 1, 2, 57- 62 (2011) 